JOURNAL OF SECURITY AND SUSTAINABILITY ISSUES

ISSN 2029-7017 print/ISSN 2029-7025 online

2019 September Volume 9 Number 1

http://doi.org/10.9770/jssi.2019.9.1(18)

Scopus

\title{
TOWARDS ECONOMIC GROWTH: THE IMPACT OF INFORMATION TECHNOLOGY ON PERFORMANCE OF SMES
}

\author{
Sheikh Muhamad Hizam Hj Sheikh Khairudin'1, Mohammad Amin ${ }^{2}$ \\ 1.2 Business School, Universiti Kuala Lumpur (UniKL) Jalan Gurney, \\ Kampung Datuk Keramat, 54000 Kuala Lumpur, Wilayah Persekutuan Kuala \\ Lumpur, Malaysia \\ E-mails: ${ }^{1}$ sheikhmhizam@unikl.edu.my,2aminmohd8844@gmail.com
}

Received 20 February 2019; accepted 20 June 2019; published 10 August 2019

\begin{abstract}
This is a conceptual article to study the economic effects of SMEs performance. It has become a widely recognized that entrepreneurs and Information Technology (IT) have become the backbone of the world's economy. In fact, entrepreneurs are commonly considered an asset for the economic development of the society as well as the country. The current studies focus on the nature, process and practice of the matter SMEs and Information Technology in entrepreneurship for the development and implementation throughout the world, and provide entrepreneurs, managers and practitioners with up-to-date, comprehensive and effective strategies for business plans with an effective method of using Information Technology in society. However, massive and ongoing transformations are characteristics of this environment and business environment, which underscores the need for greater attention to be paid to the business environment. Furthermore, modern organizations do activities in complex environment and in the meantime dynamic. This paper aims to discuss the importance of entrepreneurship in today's society. Therefore, entrepreneurs can play an important role in assisting and fostering business success to benefits the society. Extensive changes, increased complexity and competition are the most important features of today's world. In addition, Information Technology can assist the business to create value, better performance, increase productivity and quality. Finally, information technology is important to the business sector as a management tool to optimize the processing of information to produce goods and services for profits.
\end{abstract}

Keywords: Economic growth; Information Technology; SMEs; Economics; Business Performance; Value, Society

Reference to this paper should be made as follows: Sheikh Muhamad Hizam Hj Sheikh Khairudin, Mohammad Amin S. 2019. Towards economic growth: the impact of information technology on performance of SMEs, Journal of Security and Sustainability Issues 9(1): 241-255. http://doi.org/10.9770/jssi.2019.9.1(18)

JEL Classifications: D00, D01, E3

\section{Introduction}

Due to vital contributions to each country's economy, small and medium-sized enterprises (SMEs) have paid much attention in recent entrepreneurship research. The appearance of SMEs is particularly important in all developing countries where they support economic growth; improve the distribution of income, productivity, efficiency and economic structure during the economic downturn (Abdullah \& Manan, 2011; Kowo et al., 2019). Due to flexible and compatible structures, small and medium-sized enterprises (SMES) have become more important to the world (Kayadibi et al., 2013). In the era of worsen economic crisis worldwide where financial institution are merging, industries are being downsized, productions are being minimized, as a response to which inflation is rising at a high pace, unemployment is becoming a world's dilemma, money is losing worth, and in total giant economies are collapsing. However, there still exists a field/sector or an industry which is ever increasing since the time of its existence and even proving out to be a support to falling economies in this time of economic recession (Information Technology). In addition, the biggest business growth in the past 
two decades was like Facebook, Twitter, Linked In, Instagram, etc. are pretty prominent success platforms. The reason for the very fact is the diversification and advancement in the Information Technology, it has both tangible and intangible benefits that will help the society to create value and produce the results which customers demand. Technological infrastructure affects the culture, efficiency and relationships of a business. It also affects the security of confidential information and trade advantages Korauš, 2019a, 2019b; Ključnikov et al. 2019; Davidavičienè et al., 2019).

The information revolution is sweeping through economy, so no company can escape its effects. Dramatic reductions in the cost of obtaining, processing, and transmitting are changing the way doing business. However, the technologies will help the SMEs to improve and develop each day and availed globally while the rate of usage and exploitation of technology is dependent on factors which have huge influence on business. Finally, business is regarded to have the potentials to significantly increase success and performance of the work quality.

SMEs play a significant role in economies by providing a large portion of production in the rapidly changing world due to adaptability features. However, SMEs show major contribution in the development of a county's economy, its political stability as well as social uplifting. In fact, SMEs are flexible in nature, they can be established for all kind of activities of every business and are considered as a backbone of country's economy (Solesvik, 2012). The government has given much attention on the development of SMEs because of their significant role in the economic development and improvement (Khaliq et al., 2012).

Several research gaps are identified that relates to the Information Technology to improve SMEs/businesses. These are summarized as follows:

1. Despite the SMEs are the backbone of the economy that help the society to have better place.

2. SMEs and Information Technology have had an impact on multiple aspects of the business and how communities and regions grow and succeed.

3. Organizations need to understand the importance of IT improvement and development outcomes, which influence on growth and success of SMEs.

4. In fact, majority of Information Technology advancement appears in the developing world for the sake of success.

5. Organization SMEs that use IT for-business transactions and for the support of success and growth

6. The majority of businesses in the world are SMEs which adopted the information technology to improve and increase sales and revenue.

According to Manirafasha, Ndikubwimana, Zeng, Lu, \& Jing (2016), those development outcomes from IT adoption in SMEs have to be allied with the businesses. Alonso-Mendo, Fitzgerald, \& Frias-Martinez, (2009), also find that website redesign has to be allied with the SMEs businesses function. It appears so far that SMEs and individuals within have a very unique perspective towards the usage of IT development, approaches to promote IT, and expected outcomes.

\section{Literature Review and Hypotheses}

It is very essential to understand entrepreneurs in the context of emerging economies because the entrepreneurial competencies for business growth and survival in emerging economies are different from those of in developed economies (Solesvik, 2012). Majority of the SMEs are struggling to increase productivity, organizational effectiveness, sustained competitive advantages and satisfactory rates of return on investments for the society (Hussain, \& Raghavan, 2017). To increase SMEs' competitiveness in global markets, which should be financially sound and should be well connected to markets. This, however, is not going to be easy in an economy where traditional and informal practices of business management are still applied. It is evident from research that innovative technological strategies are a key resource for gaining competitive advantages, but this is challenging because some enterprises lack entrepreneurship and innovative skills. Consequently, many businesses fail and close a few days after they start (Ndikubwimana, 2016). 
SMEs are realizing the benefits of using new technologies, but some need specific support and guidance before they use digital technologies. Although the government and other development partners have rolled out a number of initiatives as far as digital technology is concerned, there seems to be a huge gap in awareness among SMEs about the changes that are inevitably brought about by technology in terms of business growth and how they should adapt to this shift. The focus has shifted from whether or not to use technology to understand which technologies can be used for what specific business purposes and also on investigating how they can best be applied in a range of contexts. In fact, SMEs are excited about the changes brought about by the use of technology in business there are also many challenges including lack of network infrastructure, lack of supports and slow unstable access to the advancement of technologies. Some SMEs do not have the bandwidth to support internet activity in their businesses. This provides a great challenge in the communication process between staff members and the management (Zandi \& Haseeb, 2019). The other challenges are poverty, not enough knowledge and lack of training on how to use digital technology. In addition, ensuring that technology is used to enable and to advance effective business practices is also a big challenge. Hence, there is a need to investigate the effects of digital technology adoption in SMEs in every country. The purpose of our study is to investigate SMEs' employees and management attitudes and perceptions about adopting and using technology in businesses to come up with the factors that are hindering its adoption and use by SMEs.

Entrepreneurship is more than the mere creation of business and the characteristics of seeking opportunities, taking risks beyond security, and having the tenacity to push an idea through reality (Schaper, 2002, Hussain, \& Raghavan, 2017). Entrepreneurship is the symbol of business tenacity and achievements. The single definition of entrepreneurship doesn't exist considering the openness and depth of entrepreneurship as a concept. (Abdullahi, 2015), consider the use of technology in business as one of the changing trends in the era of hyper business and commercialization. Entrepreneurship is the most powerful economic force to mankind (Kuratko, 2007; Hussain, \& Raghavan, 2017). Competitiveness, goal-oriented behaviour, confidence, opportunistic behaviour, intuitiveness, reality-based actions, ability to undertake certain risk and make decisions in conditions of uncertainty are other characteristics of entrepreneurship (Kuratko, 2007; Ndinguri, Machtmes, Machtmes, $\&$ Hill, 2018). Besides, entrepreneurs use technical knowledge as a vibrant resource to overcome resource shortage (Shane, 2008; Suyono, Sukoco, Setiawan, \& Rahim, 2017). According to Garcés-Galdeano, et al., (2016), states that innovation is one of the basic characteristics of a successful entrepreneur, it could be beneficial to indulge IT in the ventures. Olatunji, O. S. (2015), states that information technology (IT) plays an indispensable role in making a company successful under uncertain and turbulent economic conditions. IT and Entrepreneurship are factors of encourage in investment. The role of information technology in entrepreneurship has been studied in some parts of the world. Many factors have been identified as being associated with entrepreneurship. For example, entrepreneurial activities combine many personality traits - innovativeness, risk taking, proactiveness in the sense of doing what is necessary to realize their ideas combined with shouldering responsibility for success (Morris et al., 1996 and Caniëls et al., 2015). In fact, IT systems affect a firm's products and services, markets, product cost, and product differentiation. However, entrepreneurship is as the process of creating value by combining a unique mix of the aforementioned concepts in order to get success in business opportunity. According to Berisha-Namani, M. (2009), introduces information technology in line with social entrepreneurship as leverage for the sustainable development. Jones, P., Beynon, M. J., Pickernell, D., \& Packham, G. (2013), stated that IT has a great impact in the decision of the people with regards to their living condition in digital world. Efficiency and improvement are the importance of work success. Below conceptual framework of the study is presented (Figure 1). 


\section{Conceptual Framework}

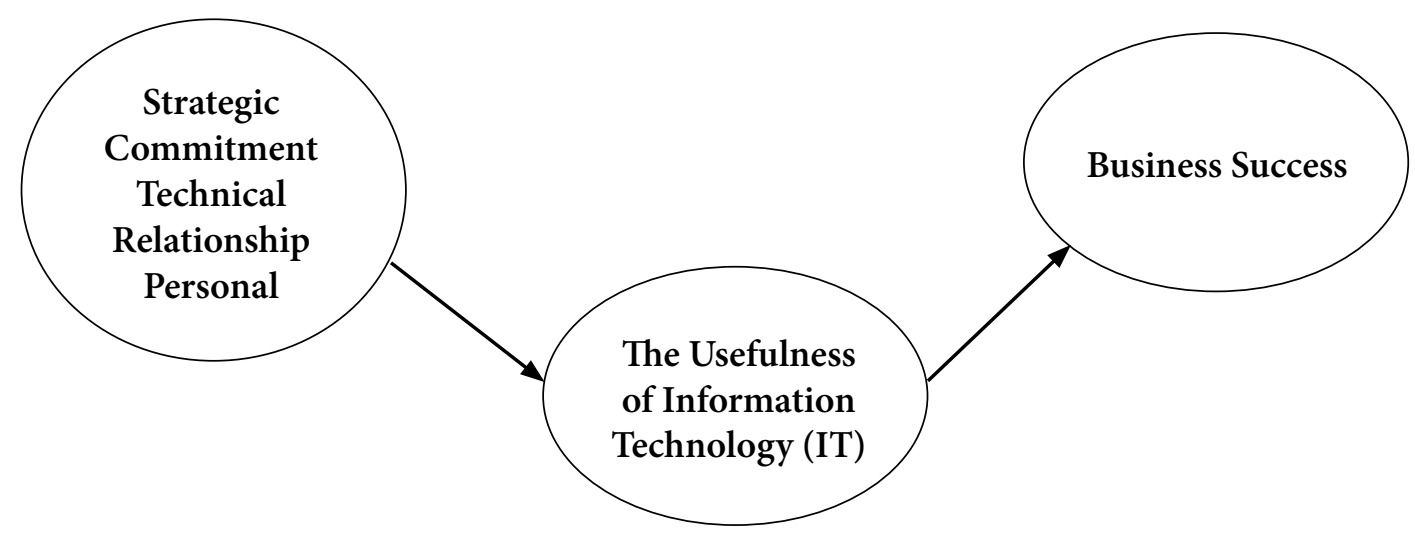

Fig. 1. Framework of the Study

There are the research hypotheses of the study:

$\mathrm{H} 1$ : The strategic competency is in significant relationship with the business success.

$\mathrm{H} 2$ : The commitment competency is in significant relationship with the business success.

H3: The technical competency is in significant relationship with the business success.

H4: The relationship competency is in significant relationship with the business success.

H5: The rpersonal competency is in significant relationship with the business success.

H6: The usefulness of information technology is in significant relationship with the business success.

H7: The usefulness of information technology mediates the relationship between strategic competency and business success.

H8: The usefulness of information technology mediates the relationship between commitment competency and business success

H9: The usefulness of information technology mediates the relationship between technical competency and business success

H10: The usefulness of information technology mediates the relationship between relationship competency and business success

H11: The usefulness of information technology mediates the relationship between personal competency and business success.

\section{Variables of the Study}

\subsection{Strategic Competency}

Strategic Competency refers to setting, evaluating, and implementing the strategies of the firm and knowledge-based competencies which including the project management, analytical thinking, and the ability to learn new things (Man et al., 2002; Mulder et al., 2014). According to Gallardo, A. R., et al. (2015), strategic competency mostly related to behaviours such as: redesigning the firm to better meet the firm's objectives, aligning current actions with strategic goals, monitoring progress toward strategic goals, evaluating results against strategic goals, and determining strategic actions by weighing costs and benefits. Strategic competency will help the firms to perform better in products and service. Furthermore, according Gallardo, et al. (2015) and Jayaram et al., (2014), strategic competency identify some competencies which are require for business success such as technical knowledge and skills, cognitive abilities, creative problem solving, communication, commitment and courage. However, it needs to understand what is tactically and operationally feasible in different situation of success and the effective business success on organization (Gallardo, et al. 2015; Mueller et al., 2015). 


\subsection{Commitment Competency}

Commitment competency refers to behaviours that drive entrepreneurs to move ahead with the business success (Man et al., 2002; Shenura et al., 2016). In fact, commitment competency vital of possessing these competencies allowed entrepreneurs to strive towards business goals and objectives of the organizations. With the development of modern economy, more and more enterprises come to realize the intimate relationship between commitment competency and organizational success, therefore, the concept commitment competency is more involved in management and becomes an effective index of prediction of organizational success. Allen et al. (1990) and Shaul et al. (2012), defined three components of commitment competencies with the following statement: success with strong affective commitment remain because they want to, those with strong continuance commitment because they need to, and those with strong normative commitment because they feel they ought to do.

\subsection{Relationship Competency}

Relationship competency is defined as the organization of different internal and external human, physical, financial, and technological resources, including team building, leading employees, training and controlling in business environment for the sake of success and profits (Man and Lau, 2002). In business environment, entrepreneurs are required to have good relationship that deal with people including suppliers, customers, employees, government authorities, stakeholders and other resources (Batselé et al. 2019). Competency refers to the individual's abilities, skills and knowledge which enhance the sales growth and profits (Stumm, \& Morgan 2012). Moreover, the relationship competency plays the roles in analysing the organizational problems, making important decisions and innovating in new processes, products and services to increase sales and profits. It also related to personal knowledge and abilities that increase the success and sales growth in firms. Besides, every entrepreneur therefore, need to possess and acquire interpersonal and communication skills. The relationship competency also relates to skills in person-to-person or individual- to-group-based interactions, such as building a context of cooperation and trust, using contacts and connections, persuasive ability, communication and interpersonal skill (Man et al., 2002). To successfully do so, the entrepreneur needs to possess competencies in relationship building, communication, persuasive, and interpersonal abilities (Gasse et al., 1997).

\subsection{Personal Competency}

Personal competency defined as the ability to maintain a high level of energy, motivate self to function at optimum level of business success, respond to constructive criticism, maintain a positive attitude, priorities tasks to manage time, identify own strength and weaknesses and match them with opportunities and threats, as well as recognize and work on own shortcomings. Moreover, personal competency includes determination and self-belief (Thompson, Hinton, 1997), self-awareness (Cherniss et al., 1998), self-control and stress tolerance (Markman et al., 1998), and self- management. It defined as knowledge, skills and abilities. Personal competency is related to the set of skills to include self-awareness, self-management, social awareness, relationship skills, and responsible decision-making (Veliu et al., 2017). However, personal competencies are an ever-evolving accumulation of related to skills and knowledge which help to achieves goals and objectives of the organizations. Personal competency are underlying characteristics of a person and consistent patterns in the way individuals behave, feel and think.

\subsection{Technical Competency}

Technical competency refers to the ability to use the tools, procedures, and techniques which require for the specialized field to achieve the objectives of the organizations (Tripathy et al., 2016). Technical com competency related to experiences, skills, and knowledge. According to Medina et al., (2014), it has a positive significant impact on sales growth. In addition, skills are based on knowledge, skills and skills that enhance business success. These competencies include work skills specifically involving methods such as processes, procedures in business success. Technical competency also related to the abilities, knowledge, skills and techniques in business environment for success and development. In fact, entrepreneurs use these competencies in business success and increasing products and services (Hasanefendic et al. 2016). And also, it refers to behaviours of 
competencies such as use specific techniques and utilize technical knowledge relevant to the business success (Rahman, 2015).

\subsection{The Usefulness of Information Technology (IT) in SMEs}

The usefulness of information technology (IT) in small and medium enterprises (SMEs) is vital on the economy's a country and it considered to be the backbone of industrial development in every nation (Saleh, \& Ndubisi, 2006; Kurnia et al., 2015). According to Adamson et al. (2007) and Morgan-Thomas (2016), IT in SMEs are drivers of economic growth, success and innovation. SME is the most popular business entities registered by entrepreneurs because of simple ownership structure, less procedural registration process and flexible in decision making process. Thus, based on the effective performance in business environment, it is considered that IT in SME has huge impact on organization development and improvement. In fact, every country is relying on the SME as the engine of economic growth and success. In this regards the engagement of knowledge, skills and abilities will ensure the success and sustainability of SMEs to increase profitability (Chang et al., 2011), and eventually will contribute to the economic growth and sales volume. Nguyen et. al. (2015), noted that information technology is one of the most important factors of any production activity and technological changes can have profound consequences.

In addition, IT knowledge, skills and abilities can be a tool to improve SMEs performance and products development. However, it is encouraging to note that the current level of understanding of IT among SMEs is reasonably well developed and succeeded. In fact, developed countries in particular has advanced immensely through the numerous benefits that IT provides. The emergence of IT has helped organizations achieve better coordination and collaboration among supply chain partners and automate the supply chain process Hsin, C., \& Papazafeiropoulou, A. (2008). However, IT particularly the Internet is having a significant impact on the operations of SMEs and it is claimed to be essential for the survival and growth of nation's economies. The ability of IT in SMEs is that to realize goals depends on how well the organization acquires, interprets, synthesizes, evaluate and understands information technology and how well its technologies supports organizational processes and performances. These technologies will continue to enable the growth and success where SME operate across national boundaries. Today, new technologies, especially Internet technology are changing the global flows of information, trade and investment and the competitive advantage of industries, services and regions. These changes are requiring from all enterprises, no matter of their size to invest in the adoption of new technology. The ability of IT in SMEs is to survive in an increasingly competitive and global environment is largely influenced upon their capacity to access information as a resource and usage of new technologies. Greater use of these technologies is often associated with improved availability of information, quality of work, effectiveness and efficiency in accomplishing tasks. IT in SMEs is very important in the development of the countries, economies and enterprises (Nguyen et al., 2015).

\subsection{Business Success}

Business success is often defined as the achievement of a favourable and desired outcome Merriam-Webster, D. (2018). Business success is the ability of the firm to achieve its stated objectives and also achievement with regards to its business goals. The goal of every business is to be successful and success is defined in various different ways. But the literature showed inconsistencies of what constitutes measure of success. Some researchers focused on use of financial indicators while others considered non-financial indicators of success. The former asserted on traditional financial measures of performance such as turnover of sales, profitability, return on investment to predict the success and failure of a firm (Brüderl, \& Preisendörfer, 1998; Oyeku et al., 2014). The achievement of goals and objectives for better quality services by human endeavours Oyeku et al. (2014). The researchers who prefer financial measures of success usually argued that for the success of the organizations, it is vital to generate profits and to show some level of growth which is represented by volume of their sales (Gimm et al., 2000). Wiklund, J. (1999) suggested that both aspects of performances i.e financial and nonfinancial complement each other and indicate the actual performance of business. Lucky (2011) Related to efficiency, growth, profit, size, liquidity, market share and leverage. Thus, it is not sufficient to focus only on 
financial performance while neglecting the other measures that indicate the business success as well (Buttner, \& Moore, (1997). Watson, \& Robinson, (2003) argued that both the financial and non-financial dimensions of organizational performance are needed to be emphasized in the future studies to capture total organizational performance. Thus, this paper also includes both financial as well as non-financial indicators of SMEs business success in its proposed conceptual model. The achievement of goals and objectives of a company, which is not explicitly defined (Erickson et al., 1989).

\section{Methodology}

The following section provides the data analysis including the illustration and discussion about the research findings. For the purpose of data analysis, the Structural Equation Modeling is used in this study. The Structural equation modeling is a statistical multivariate technique for analyzing the structural associations. It is a combination of multiple regression analysis and factor analysis and is generally employed to analyze the existence of structural association between the measured and the latent constructs. Researchers prefer to use this method because it is capable of estimating multiple as well as interrelated associations in a single analysis (Hair et al., 1998). After the selection of methodology, sample collection was done using a method of cluster sampling. For the sample size estimation, the first step is the total population determination. The sample size for this study is determined using Krejcie and Morgan's (1970) sample size table. Gay and Diehl (1992) suggested that the required sample size for a study depends upon the type of research i.e. experimental, descriptive or correlational. The present study has chosen SEM as it is a second-generation statistical technique, providing robust results. Besides, SEM-PLS allows the statistical modeling and estimation of complex phenomena. Therefore, became the most preferred method to assess the theoretical models under quantitative researches. It enables researchers to assess the complex and advanced theoretical models without much dependency on statistical methods. Finally, SEM software is also user-friendly, just as other Window-based software. SEM model consists of formative and reflective constructs. The objective is to determine the prediction among the constructs. For many years, researchers have been using EQS, AMOS, and LISREL as the software tools for performing such analysis. However, PLS-SEM is a useful alternative to CB-SEM, with distinctive methodological features. The estimated population size is 22000 and the selected sample size is 377 . Thus, 377 survey questionnaires were distributed, and 269 questionnaires were received back, thus the response rate came out to be $71 \%$, which is above the threshold level $(45 \%-50 \%)$. The gathered questionnaires were then undergoing the process of further evaluation. From the total respondents chosen for the study, there were 198 male respondents and 71 female respondents, with the average age of 43 years. On average, $58 \%$ of the total respondents were found to be part of the operational department for past 10 years.

\section{Results and Discussion}

\section{Results}

SEM-PLS involves two types of models: i.e. Measurement model and the Structural model. The measurement model shows how the measured variables are related to represent a specific theory. Whereas, the structural model shows whether the constructs involved in the model are related to other constructs. It is also known as causal modeling, since it tests the assumed causal association between the constructs. The first step in PLSSEM estimation is determining the measurement model also referred as CFA i.e. confirmatory factor analysis. In CFA, the theoretical measurement is compared with the proposed reality model. The CFA is usually used to assess how well the variables involved in the model are observed. The CFA's result must be related to the validity of the construct (See: Figure 2 'Measurement Model' and Table 1 'Outer loadings'). 
JOURNAL OF SECURITY AND SUSTAINABILITY ISSUES

ISSN 2029-7017 print/ISSN 2029-7025 online

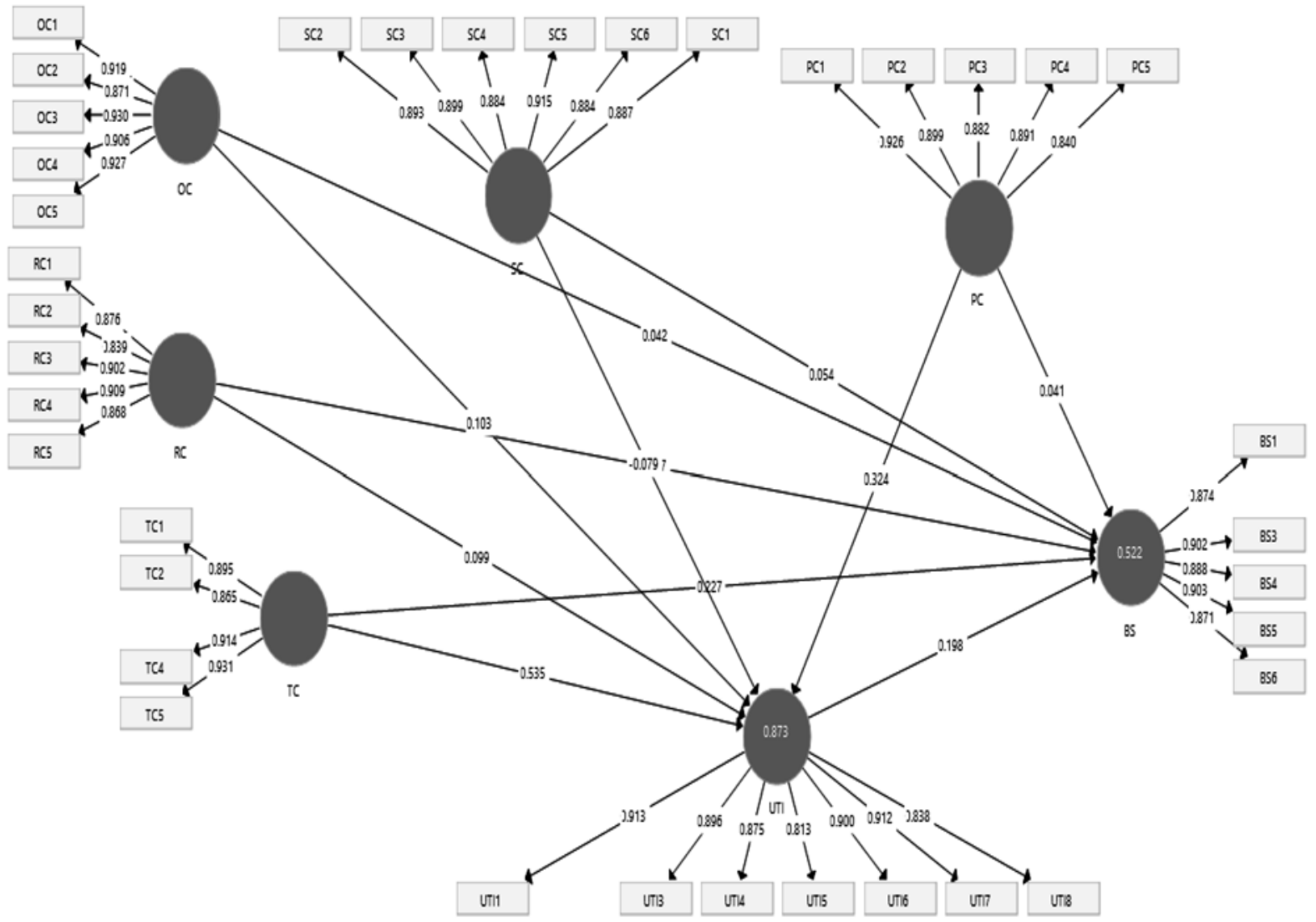

Fig. 2. Measurement Model

Table 1. Outer loadings

\begin{tabular}{|c|c|c|c|c|c|c|c|}
\hline & BS & $\mathrm{OC}$ & $\mathrm{PC}$ & $\mathrm{RC}$ & $\mathrm{SC}$ & $\mathrm{TC}$ & UTI \\
\hline BS1 & 0.874 & & & & & & \\
\hline BS3 & 0.902 & & & & & & \\
\hline BS4 & 0.888 & & & & & & \\
\hline BS5 & 0.903 & & & & & & \\
\hline BS6 & 0.871 & & & & & & \\
\hline OC1 & & 0.919 & & & & & \\
\hline $\mathrm{OC} 2$ & & 0.871 & & & & & \\
\hline OC3 & & 0.930 & & & & & \\
\hline OC4 & & 0.906 & & & & & \\
\hline OC5 & & 0.927 & & & & & \\
\hline $\mathrm{PC} 1$ & & & 0.926 & & & & \\
\hline PC2 & & & 0.899 & & & & \\
\hline PC3 & & & 0.882 & & & & \\
\hline PC4 & & & 0.891 & & & & \\
\hline PC5 & & & 0.840 & & & & \\
\hline $\mathrm{RC} 1$ & & & & 0.876 & & & \\
\hline $\mathrm{RC} 2$ & & & & 0.839 & & & \\
\hline $\mathrm{RC} 3$ & & & & 0.902 & & & \\
\hline $\mathrm{RC} 4$ & & & & 0.909 & & & \\
\hline RC5 & & & & 0.868 & & & \\
\hline $\mathrm{SC} 2$ & & & & & 0.893 & & \\
\hline $\mathrm{SC} 3$ & & & & & 0.899 & & \\
\hline
\end{tabular}




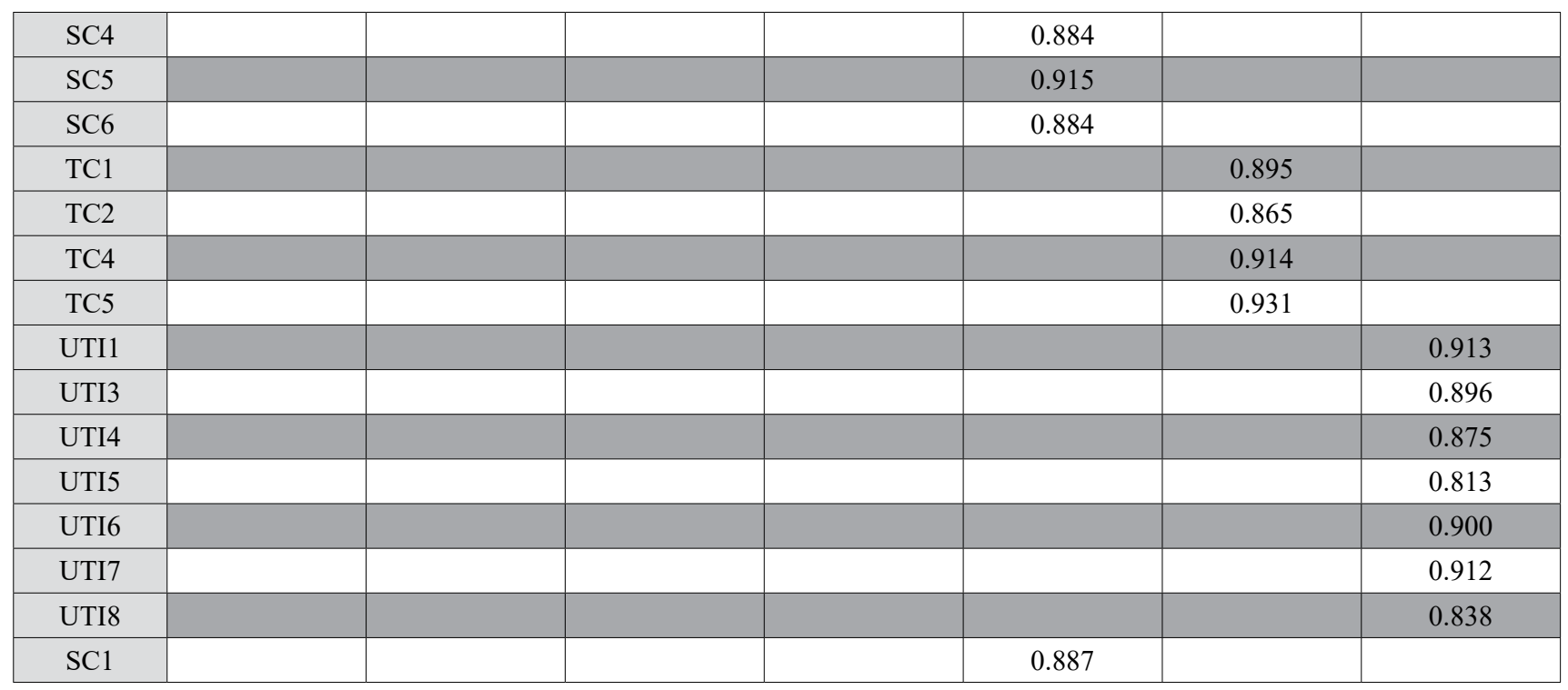

Strong correlation between the variables is expected since all the items have dynamic nature. The study estimated each element using formative, reflective and structural modelling. Fornell-Larcker criterion was used to determine the model validity. The discriminant validity criterion is a powerful and a widely used measure employed in research studies. Discriminant validity is the extent a construct is empirically distinctive from the other constructs. It also analyzes the correlation among the concepts (Hair et al., 2014) and whether these concepts possess the potential to overlap (Ramayah et al., 2018). (See below Table 2 'Discriminant Validity').

Table 2. Discriminant Validity

\begin{tabular}{|c|c|c|c|c|c|c|c|}
\hline & BS & OC & PC & RC & SC & TC & UTI \\
\hline BS & 0.888 & & & & & & \\
\hline OC & 0.614 & 0.911 & & & & & \\
\hline PC & 0.650 & 0.649 & 0.938 & & & & \\
\hline RC & 0.653 & 0.916 & 0.695 & 0.929 & & & \\
\hline SC & 0.616 & 0.892 & 0.690 & 0.911 & 0.894 & & \\
\hline TC & 0.677 & 0.670 & 0.921 & 0.725 & 0.674 & 0.931 & \\
\hline UTI & 0.677 & 0.692 & 0.897 & 0.734 & 0.687 & 0.921 & 0.879 \\
\hline
\end{tabular}

Thus, the square roots of AVE (average variance extracted) were also compared against the correlations of latent variables to assess the Fornell-Larcker criterion. For each variable, this square root of AVE must exhibit value greater than the correlation it have with other latent constructs (Hair et al., 2014). The value for AVE square root turned out as required and in line with the criterion. Therefore, representing the discriminant validity. The outer and cross loadings for the current study were found to be same. The cross-loadings determine the presence of any correlation between the items of the constructs, Table 2 presents the discriminant validity among the variables and the constructs. The reliability index or the internal consistency value must also be above 0.70 to confirm the model reliability (See below Table 3).

Table 3. Reliability

\begin{tabular}{|c|c|c|c|c|}
\hline & Cronbach's Alpha & rho_A & Composite Reliability & Average Variance Extracted (AVE) \\
\hline BS & 0.933 & 0.936 & 0.949 & 0.788 \\
\hline OC & 0.948 & 0.951 & 0.960 & 0.829 \\
\hline PC & 0.933 & 0.934 & 0.949 & 0.773 \\
\hline RC & 0.926 & 0.928 & 0.944 & 0.799 \\
\hline SC & 0.950 & 0.925 & 0.960 & 0.813 \\
\hline TC & 0.923 & 0.953 & 0.945 & 0.773 \\
\hline UTI & 0.951 & 0.960 & \\
\hline
\end{tabular}


The next step in PLS-SEM is the structural model estimation. This step involves drawing structural paths between the constructs. To represent structural relationship (hypothesized) between the constructs, only a singleheaded arrow was used. Structural model was then analyzed through observing the structural path between dependent, independent and the moderating constructs. The model also explains the relation existing between the latent constructs. Whereas, the measurement model explains the occurrence of association among the constructs and their indicating variables (i.e. the outer model). Structural model also determines the direct as well as indirect effects of the involved variables. Following is the structural model of this study (Figure 3):

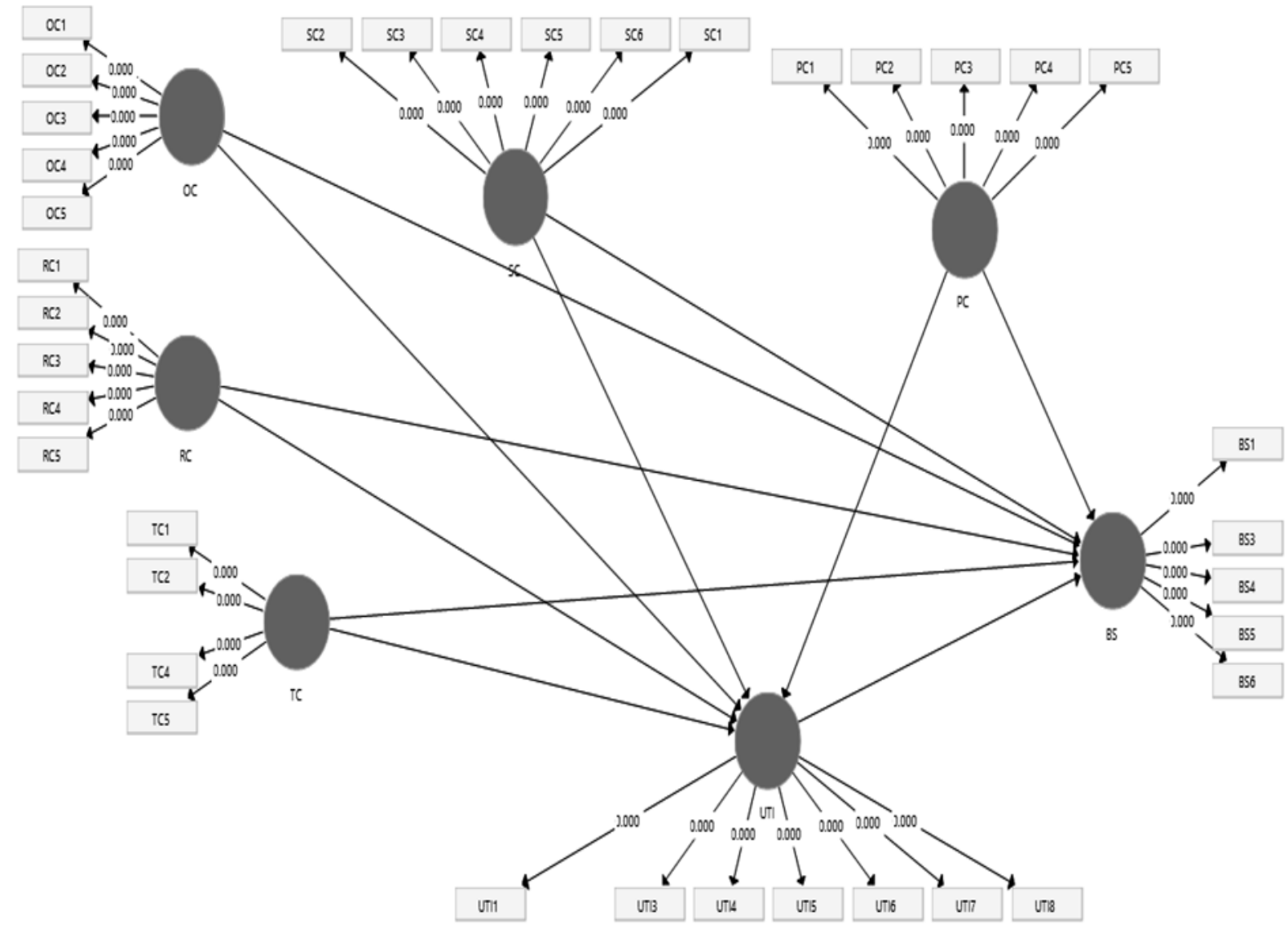

Figure 3. Structural model

Table 4. Direct Relationship

\begin{tabular}{|c|c|c|c|c|c|}
\hline & Original Sample (O) & Sample Mean & SD & $\begin{array}{c}\text { T Statistics }(\mid \mathrm{O} / \\
\text { STDEV } \mid)\end{array}$ & P-Value \\
\hline OC -> BS & 0.062 & 0.062 & 0.172 & 3.360 & 0.000 \\
\hline OC -> UTI & 0.103 & 0.106 & 0.066 & 3.552 & 0.000 \\
\hline PC - > BS & 0.105 & 0.102 & 0.121 & 3.870 & 0.000 \\
\hline PC -> UTI & 0.324 & 0.322 & 0.075 & 4.299 & 0.000 \\
\hline RC - > BS & 0.247 & 0.250 & 0.168 & 3.470 & 0.000 \\
\hline RC -> UTI & 0.099 & 0.099 & 0.096 & 3.027 & 0.000 \\
\hline SC -> BS & 0.039 & 0.037 & 0.136 & 3.285 & 0.000 \\
\hline SC -> UTI & -0.079 & -0.074 & 0.092 & 3.854 & 0.000 \\
\hline TC -> BS & 0.333 & 0.336 & 0.127 & 3.616 & 0.009 \\
\hline TC -> UTI & 0.535 & 0.530 & 0.078 & 3.872 & 0.000 \\
\hline UTI -> BS & 0.198 & 0.212 & 0.189 & 4.049 & 0.000 \\
\hline
\end{tabular}


Table 5. Indirect Relationship

\begin{tabular}{|c|c|c|c|c|c|}
\hline & Original Sample (O) & Sample Mean (M) & SD & $\begin{array}{c}\text { T Statistics } \\
(\mid \mathrm{O} / \text { STDEV })\end{array}$ & P Values \\
\hline OC -> UTI -> BS & 0.020 & 0.020 & 0.025 & 0.816 & 0.000 \\
\hline PC -> UTI -> BS & 0.064 & 0.067 & 0.063 & 1.023 & 0.000 \\
\hline RC -> UTI -> BS & 0.020 & 0.024 & 0.035 & 0.552 & 0.000 \\
\hline SC -> UTI -> BS & -0.016 & -0.019 & 0.031 & 0.506 & 0.000 \\
\hline TC - > UTI -> BS & 0.106 & 0.115 & 0.106 & 1.000 & 0.000 \\
\hline
\end{tabular}

Afterwards, the study estimated the mediation level, to determine any indirect effects. For assessing the relationship significance, bootstrapping analysis was carried out with 1000 sample observations. The p-value is significant at 5\%; all hypotheses exhibited significant results are 5\% level of significance, therefore, representing the acceptance of all hypotheses In addition, the study also found the moderating role of customer response in the relationship between external supply chain performance and agile supply chain, as presented in Table 4 and Table 5. Mediation results have shown significant values for $\mathrm{t}(\mathrm{t}>1.96)$ and $\mathrm{p}(\mathrm{p}<0.05)$, thus accepting the H3 hypotheses.

Table 6. R-Square

\begin{tabular}{|c|c|}
\hline & R Square \\
\hline BS & 0.522 \\
\hline UTI & 0.873 \\
\hline
\end{tabular}

Finally, the predictive power of the variables is observed by estimating the coefficient of determination $\left(\mathrm{R}^{2}\right)$. The $\mathrm{R}^{2}$ for this research is $52 \%$, which is the moderate level, therefore, indicating that 52 percent variation in dependent variable is explained by the independent variables (Table 6). Range of $R^{2}$ is $0-1$, where 0 represent no predictive accuracy and 1 represents greater or substantial predictive power.

\section{Conclusion}

Every business in this world is born out of entrepreneurship. Entrepreneurship has been the sprouting ground for various discoveries, inventions, innovations, products and processes and is source and engine of economic growth. From the context of this study, a sound conclusion can be drawn with emphasis that IT has a great influence on productivity in the entrepreneurship. Hence, Information Technology has influence to make changes in process and productivity which in turn boost profitability and success. In the same vein, the use of Information Technology in entrepreneurship opens up new opportunities, reduces inventories with the use of Information Technology as well as makes services more tradable (Brüderl, J., \& Preisendörfer, P. 1998). Furthermore, Information Technology has the potential to improve the core business in every step of business process, through the use of information technology in entrepreneurship can gain from developing capabilities for managing information, intensive resources, reduced transaction costs, develop capacity for information gathering and dissemination of international scale and gain access to rapid flow of information. In addition, entrepreneur in SMEs sector is a very important character who has the strength to boost the economy of a country. The conductive milieu created for innovate which can optimize the performance of the business. Entrepreneurship is a concept which is not detachable from the concept of innovation. Innovation is not coming free but its origins at human mind with the aid of knowledge absorbed from the environment. Business innovation can be categorized to four basic concepts according to literature namely; product, process, market and organizational innovations. Innovation refers a newness which can be radical or incremental. Mentioned innovations may differentiate one organization from another. That difference may attract the customers for the innovative organization. Further these innovations may support entrepreneurs to identify unseen markets, develop new processes and introduce new organizational structure to adapt those processes and to develop quality products with low cost to win competition. 


\section{References}

Abdullah, M. A., Manan, S. K. A., (2011). Small and Medium Enterprises and Their Financing Patterns: Evidence from Malaysia. Journal of Economic Cooperation and Development, 32(2), 1-18. https://doi.org/10.6007/IJARBSS/v8-i3/3910

Abdullahi, M.S. (2015). The nature of Small and Medium Scale Enterprises (SMEs): Government and financial institutions support in Nigeria. International Journal of Academic Research in Business and Social Sciences, 5(3), 525-53. https://doi.org/10.6007/IJARBSS/ v5-i3/1536

Adamson, P., Andreopoulos, C., Arms, K. E., Armstrong, R., Auty, D. J., Avvakumov, S., ... \& Barr, G. (2007). Measurement of neutrino velocity with the MINOS detectors and NuMI neutrino beam. Physical Review D, 76(7), 072005. https://doi.org/10.1103/ PhysRevD.76.072005

Allen, N. J., \& Meyer, J. P. (1990). The measurement and antecedents of affective, continuance and normative commitment to the organization. Journal of occupational psychology, 63(1), 1-18.

Alonso-Mendo, F., Fitzgerald, G., \& Frias-Martinez, E. (2009). Understanding web site redesigns in small-and medium-sized enterprises (SMEs): a UK-based study on the applicability of e-commerce Stage Models. European Journal of Information Systems, 18(3), $264-279$. https://doi.org/10.1057/ejis.2009.14

Batselé, E., Stefaniak, N., \& Fantini-Hauwel, C. (2019). Resting heart rate variability moderates the relationship between trait emotional competencies and depression. Personality and Individual Differences, 138, 69-74. https://doi.org/10.1016/j.paid.2018.09.020

Berisha-Namani, M. (2009). The role of information technology in small and medium sized enterprises in Kosova. In Fulbright academy conference (pp. 1-8). https://doi.org/10.1.1.528.7377\&rep=rep1\&type=pdf

Brüderl, J., \& Preisendörfer, P. (1998). Network support and the success of newly founded business. Small business economics, 10(3), 213-225. https://doi.org/10.1023/A:1007997102930

Buttner, E. H., \& Moore, D. P. (1997). Women's organizational exodus to entrepreneurship: self-reported motivations and correlates with success. Journal of small business management, 35, 34-46.

Caniëls, M. C., Lenaerts, H. K., \& Gelderman, C. J. (2015). Explaining the internet usage of SMEs: the impact of market orientation, behavioural norms, motivation and technology acceptance. Internet Research, 25(3), 358-377.

Chang, L. M., Chang, S. I., Ho, C. T., Yen, D. C., \& Chiang, M. C. (2011). Effects of IS characteristics on e-business success factors of small-and medium-sized enterprises. Computers in Human Behavior, 27(6), 2129-2140. https://doi.org/10.1016/j.chb.2011.06.007

Cherniss, C., Goleman, D., Emmerling, R., Cowan, K., \& Adler, M. (1998). Bringing emotional intelligence to the workplace. New Brunswick, NJ: Consortium for Research on Emotional Intelligence in Organizations, Rutgers University.

Davidavičienė, V., Raudeliūnienė, J., Tvaronavičienė, M., Kaušinis, J. (2019). The importance of security aspects in consumer preferences in electronic environment. Journal of Security and Sustainability Issues, 8(3), 399-411. http://doi.org/10.9770/jssi.2019.8.3(9)

Erickson, S. J., Hendrix, L. E., Massaro, B. M., Harris, G. J., Lewandowski, M. F., Foley, W. D., \& Lawson, T. L. (1989). Color Doppler flow imaging of the normal and abnormal orbit. Radiology, 173(2), 511-516. https://doi.org/10.1148/radiology.173.2.2678264

Garcés-Galdeano, L., Larraza-Kintana, M., García-Olaverri, C., \& Makri, M. (2016). Entrepreneurial orientation in family firms: the moderating role of technological intensity and performance. International Entrepreneurship and Management Journal, 12(1), 27-45. https://doi.org/10.1007/s11365-014-0335-2

Gimm, O., Perren, A., Weng, L. P., Marsh, D. J., Yeh, J. J., Ziebold, U., ... \& Mutter, G. L. (2000). Differential nuclear and cytoplasmic expression of PTEN in normal thyroid tissue, and benign and malignant epithelial thyroid tumors. The American journal of pathology, 156(5), 1693-1700. https://doi.org/10.1016/S0002-9440(10)65040-7

Hasanefendic, S., Heitor, M., \& Horta, H. (2016). Training students for new jobs: The role of technical and vocational higher education and implications for science policy in Portugal. Technological Forecasting and Social Change, 113, 328-340.

Hsin, C., \& Papazafeiropoulou, A. (2008). Adoption of supply chain management technologies by small and medium enterprises in the manufacturing sector. ECIS 2008 Proceedings. https://doi.org/10.1016/j.sbspro.2012.11.173

Hussain, M. F. B. M., \& Raghavan, S. (2017). Interrelationships among Information System Quality, Intention to Use, Perceived Usefulness, Technology Readiness and their Effect on E-Commerce Adoption among SMEs. ANVESHAK-International Journal of Management, 6(1), 122-137. https://doi.org/10.15410/aijm/2017/v6i1/120840 
Jayaram, J., Dixit, M., \& Motwani, J. (2014). Supply chain management capability of small and medium sized family businesses in India: A multiple case study approach. International Journal of Production Economics, 147, 472-485.

Jones, P., Beynon, M. J., Pickernell, D., \& Packham, G. (2013). Evaluating the impact of different training methods on SME business performance. Environment and Planning C: Government and Policy, 31(1), 56-81. https://doi.org/10.1068/c12113b

Kayadibi, S., Polat, R., \&Fidan, Y. (2013). Small and Medium-Sized Business in Malaysian Economy: Case of Turkish Entrepreneurs in Kuala Lumpur. Business Economy, 31, 265-281.

Khaliq, A., Matloob, A., Ahmad, N., Rasul, F., \& Awan, I. U. (2012). Post emergence chemical weed control in direct seeded fine rice. J. Anim. Plant Sci, 22(1101), e1106.

Ključnikov, A., Mura, L., Sklenár, D. (2019). Information security management in SMEs: factors of success. Entrepreneurship and Sustainability Issues, 6(4), 2081-2094. http://doi.org/10.9770/jesi.2019.6.4(37)

Korauš, A., Gombár, M., Kelemen, P., Backa, S. (2019a). Using quantitative methods to identify insecurity due to unusual business operations. Entrepreneurship and Sustainability Issues, 6(3), 1101-1012. http://doi.org/10.9770/jesi.2019.6.3(3)

Korauš, A., Gombár, M., Kelemen, P., Polák, J. 2019b. Analysis of respondents’ opinions and attitudes toward the security of payment systems. Entrepreneurship and Sustainability Issues, 6(4), 1987-2002. http://doi.org/10.9770/jesi.2019.6.4(31)

Kowo, S. A., Adenuga, O. A. O., Sabitu, O.O. 2019. The role of SMEs development on poverty alleviation in Nigeria. Insights into Regional Development, 1(3), 214-226._https://doi.org/10.9770/ird.2019.1.3(3)

Kuratko, D. F. (2007). Entrepreneurial leadership in the 21st century: Guest editor's perspective. Journal of Leadership \& Organizational Studies, 13(4), 1-11. https://doi.org/10.1177/10717919070130040201

Kurnia, S., Choudrie, J., Mahbubur, R. M., \& Alzougool, B. (2015). E-commerce technology adoption: A Malaysian grocery SME retail sector study. Journal of Business Research, 68(9), 1906-1918. https://doi.org/10.1016/j.jbusres.2014.12.010

Man, T. W., Lau, T., \& Chan, K. F. (2002). The competitiveness of small and medium enterprises: a conceptualization with focus on entrepreneurial competencies. Journal of Business Venturing, 17(2), 123-142. https://doi.org/10.1016/S0883-9026(00)00058-6

Manirafasha, E., Ndikubwimana, T., Zeng, X., Lu, Y., \& Jing, K. (2016). Phycobiliprotein: potential microalgae derived pharmaceutical and biological reagent. Biochemical Engineering Journal, 109, 282-296. https://doi.org/10.1016/j.bej.2016.01.025

Markman, G. D., \& Baron, R. A. (1998). Social skills and entrepreneurs' financial success: evidence that the ability to get along with others really matters. Frontiers of entrepreneurship research, 88-102. https://doi.org/10.1177/0149206307312513

Medina, S., Dominguez-Perles, R., Gil, J. I., Ferreres, F., \& Gil-Izquierdo, A. (2014). Metabolomics and the diagnosis of human diseases-A guide to the markers and pathophysiological pathways affected. Current medicinal chemistry, 21(7), 823-848.

Merriam-Webster, D. (2018). America’s most-trusted online dictionary. (2017). www.Merriam-webster.com

Morris, M. H., \& Sexton, D. L. (1996). The concept of entrepreneurial intensity: Implications for company performance. Journal of Business Research, 36(1), 5-13. https://doi.org/10.1016/0148-2963(95)00158-1

Mulder, K. A., King, D. J., \& Innis, S. M. (2014). Omega-3 fatty acid deficiency in infants before birth identified using a randomized trial of maternal DHA supplementation in pregnancy. PLoS One, 9(1), e83764. https://doi.org/10.1371/journal.pone.0083764

Ndinguri, E., Machtmes, K., Machtmes, R. J., \& Hill, J. I. (2018). Entrepreneurs and Technology: Use and Access of Technology for Idea Generation. In Entrepreneurship, Collaboration, and Innovation in the Modern Business Era (pp. 22-39). IGI Global. https://doi. org/10.4018/978-1-5225-5014-3.ch002

Nguyen, T. H., Newby, M., \& Macaulay, M. J. (2015). Information technology adoption in small business: Confirmation of a proposed framework. Journal of Small Business Management, 53(1), 207-227. https://doi.org/10.1111/jsbm.12058

Olatunji, O. S. (2015). The impact of information communication technology on small and medium scale enterprises productivity in Nigeria.

Oyeku, O. M., Oduyoye, O., Asikhia, O., Kabuoh, M., \& Elemo, G. N. (2014). On entrepreneurial success of small and medium enterprises (SMEs): A conceptual and theoretical framework. Journal of Economics and Sustainable Development, 5(16), 14-23.

Saleh, A. S., \& Ndubisi, N. O. (2006). An evaluation of SME development in Malaysia. International review of business research papers, 2(1), 1-14. https://doi.org/10.1016/j.ijpe.2013.08.016 
Schaper, M. (2002). The challenge of environmental responsibility and sustainable development: Implications for SME and entrepreneurship academics. Radical changes in the world: Will SMEs soar or crash, 541-553.

Shane, S. A. (2008). The illusions of entrepreneurship: The costly myths that entrepreneurs, investors, and policy makers live by. Yale University Press.

Shaul, L., \& Tauber, D. (2012). CSFs along ERP life-cycle in SMEs: a field study. Industrial Management \& Data Systems, 112(3), 360384. https://doi.org/10.1111/j.2044-8325.1990.tb00506.x

Shenura, S., Haile, A., \& Negash, E. (2016). Prospects of Entrepreneurial Competencies of Micro and Small Enterprise in Jimma Zone, Ethiopia. Global Journal of Management and Business Research.

Solesvik, M. (2012). Entrepreneurial competencies in emerging economy context. In 17th Nordic Conference on Small Business Research, Helsinki. 23-25 May.

Stumm, W., \& Morgan, J. J. (2012). Aquatic chemistry: chemical equilibria and rates in natural waters (Vol. 126). John Wiley \& Sons.

Suyono, J., Sukoco, A., Setiawan, M. I., \& Rahim, R. (2017). Impact of GDP Information Technology in Developing of Regional Central Business (Case 50 Airports IT City Development in Indonesia). In Journal of Physics: Conference Series (Vol. 930, No. 1, p. 012045). IOP Publishing.

Thompson, J. L., \& Hinton, M. (1997). Antibacterial activity of formic and propionic acids in the diet of hens on Salmonellas in the crop. British poultry science, 38(1), 59-65. https://doi.org/10.1080/00071669708417941

Tripathy, S., Aich, S., Chakraborty, A., \& Lee, G. M. (2016). Information technology is an enabling factor affecting supply chain performance in Indian SMEs: a structural equation modelling approach. Journal of Modelling in Management, 11(1), 269-287. https:// doi.org/10.1108/JM2-01-2014-0004

Veliu, L., Manxhari, M., Demiri, V., \& Jahaj, L. (2017). The influence of leadership styles on employee's performance. Management (16487974), 31(2)

Volery, T., Mueller, S., \& von Siemens, B. (2015). Entrepreneur ambidexterity: A study of entrepreneur behaviours and competencies in growth-oriented small and medium-sized enterprises. International Small Business Journal, 33(2), 109-129. https://doi. org/10.1177/0266242613484777

Watson, J., \& Robinson, S. (2003). Adjusting for risk in comparing the performances of male-and female-controlled SMEs. Journal of business venturing, 18(6), 773-788. https://doi.org/10.1016/S0883-9026(02)00128-3

Wiklund, J. (1999). The sustainability of the entrepreneurial orientation — performance relationship. Entrepreneurship theory and practice, 24(1), 37-48. https://doi.org/10.1177/104225879902400103

Zandi, G., \& Haseeb, M. (2019). The importance of green energy consumption and agriculture in reducing environmental degradation: Evidence from sub-Saharan African countries. International Journal of Financial Research, 10(5), 215-227. 


\section{Dr. Sheikh Muhamad Hizam Hj Sheikh KHAIRUDIN DEPUTY DEAN (ACADEMIC AND TECHNOLOGY) AND SENIOR LECTURER}

DBA Management, University Kebangsaan Malaysia

MBA General Business, Ohio University, USA

BSc. Agriculture (Hons), University Pertanian Malaysia

Dr. Sheikh Muhamad Hizam Bin Hj. Sheikh Khairuddin is a Senior Lecturer at the Universiti Kuala Lumpur (UniKL) Business School. He has over 20 years of entrepreneurship, industrial and academic experiences. He was involved in the agribusiness; manufacturing; and air logistic sectors dealing with multinational clients with the likes of Intel, IBM, Motorola, etc. He has published his research papers in several high impact journals and conferences. He is also an external examiner to several universities and supervisor to MBA and PhD students. He also holds the posts of Internship Coordinator, Head of Research Cluster, and Editorial Board member for journal UBIS. His teaching and research interests are in the fields of Human Resource Management, Organizational Behavior, and Stress Management.

\section{Mohammad AMIN (PhD Candidate at UniKL)}

Master of Management (GSM IIUM)

Bachelor of Information Technology (IIUM)

Mohammad Amin is currently PhD student at Universiti Kuala Lumpu (UniKL) Business School. He has some working experience during and after study in the field of Information Technology (IT) and Management in Malaysia. He so far published some of his research papers in Scopus Indexed high impact journals and conferences. Meanwhile, beside his $\mathrm{PhD}$, he is also a research assisstat and organizing conferences. So far, he was secretariat of two conferences for last year and this year. He is seeking more knowlegede on research and publication to development himself to be better researcher for the future. 